\title{
Considerações Sobre o Cativeiro do "Negro da Terra" no Brasil Quinhentista
}

Mário Maestri

Foram americanos escravizados que labutaram nas primeiras roças, fazendas e engenhos das costas brasílicas. Décadas após a fundação das donatarias, o esforço produtivo colonial assentava-se sobre os ombros dos brasis. Apenas nos primeiros anos do século XVII, o africano suplantou numericamente o americano como força de trabalho nas mais ricas donatárias. Pernambuco, a primeira capitania açucareira, efetuou esta substituição alguns anos antes. Nas colônias mais pobres, o nativo feitorizado continuou desempenhando um importante papel produtivo. Em forma decrescente, tal situação se manteve mesmo após 1755, ano em que o marquês de Pombal proibiu a escravização de todo e qualquer "índio".

Ao longo do século XVI, a escravidão foi essencialmente "vermelha". Não há estimativas sobre o número de brasis submetidos ao trabalho compulsório no Quinhentos. Certamente algumas centenas de milhares. A grande maioria desta população era de cultura tupi-guarani. Com o decréscimo das comunidades que senhoreavam as costas, os portugueses penetraram os sertões e "desceram" povos - demograficamente menos significativos - de cultura jê e outras. A partir de 1630 , quando os holandeses invadiram Pernambuco e se apoderaram dos principais portos lusitanos na África, houve um forte renascimento da caça e do tráfico de brasis. Os vicentinos tomaram o rumo do Sul e prearam milhares de guaranis das missões jesuíticas.

Nas últimas décadas do Quinhentos, cativos africanos começaram a ser desembarcados, aos magotes, nos portos coloniais e o escravismo 
começou a assumir um caráter crescentemente negro. A partir de meados do século XVII, este processo estava tendencialmente consolidado. A escravidão vermelha se reduziria a um fenômeno marginal restrito sobretudo às regiōes da colônia onde não vingou uma forte economia mercantil. Zonas demasiadamente pobres para comprarem os caros es-cravos africanos. Durante este tempo, aprofundou-se o processo de decréscimo demográfico relativo e absoluto das populações nativas, agredidas pela expansão da colonização.

Em meados do Oitocentos, os povos quinhentistas tornaram-se tema central da nascente literatura brasileira. Serviram na construção ficcional dos mitos fundadores da nacionalidade, no momento em que a elite nacional procurava diferenciar-se da lusitana. Sobre tal processo, assinala N.W. Sodré: "Esmiuçando as raízes e os fundamentos do indianismo, ficaremos por vezes surpreendidos ao encontrar a origem de preconceitos, de tendências, de motivações que nos pareciam inexplicáveis, simples evasões, destituídas aparentemente de sentido, desprovidas de suportes objetivos, nuas de carnaduras, reduzidas a meras construções, sem nenhum laço com a realidade." [SODRÉ, 1969: 255.]

No momento em que se estrutura o "indianismo literário", os tupinambás faziam parte de um distante momento histórico e as elites haviam construído leituras hagiográfricas - mediadas pela visão iluminista do "índio bom" - sobre os povos da costa, sabre a ocupação territorial e sobre os primeiros tempos coloniais. Enriquecidos, transformados, refinados, estes mitos alcançam a atualidade e, difundidos pelos veículos de formação de opinião, fecudam o alienado "inconsciente histórico" nacional. O resultado é a romântica e preconceituosa visão atual do "índio" brasileiro.

A substituição dos brasis pelos africanos é um dos fenômenos menos estudados da história brasileira. $\mathrm{O}$ desconhecimento das razões desta transição ensejou difundidas explicações preconceituosas da nossa historiografia. É moeda corrente a idéia de que os brasis teriam sofrido apenas transitoriamente o cativeiro. Eles teriam sido substituídos, muito cedo, pelos africanos. Tal "revezamento" se deveria à "inadaptabilidade" do "índio" ao cativeiro. Os brasis resistiriam à escravidão. Morreriam como moscas quando arrancados da vida "livre" que teriam conhecido nas "florestas". Ao contrário, os africanos se teriam mostrado ótimos escravos: dóceis, resistentes, resignados, alegres. 
Visão ideológica

Sub-repticiamente, criavam-se atributos proprios à natureza humana "negra" e "indígena". Construía-se para o "negro" uma essência escrava. Ele deixava de ser um trabalhador feitorizado para tornar-se um escravo. Ele "nascia" escravo e não era reduzido à escravidão. Desprovido dos atributos superiores do europeu - agressividade, amor à liberdade, iniciativa, etc. - , possuiria qualidades que o destinavam ao trabalho braçal e à obediência - fortaleza física, docilidade, pouca inteligência, etc. $\mathrm{O}$ "índio" era reduzido à situação de indivíduo próprio às selvas e impróprio à civilização.

Varnhagen fala dos brasis como populações "mais ou menos errantes" que "desfrutavam, sem os benefícios da paz nem da cultura do espírito, do fértil e formoso solo do Brasil - antes que outras mais civilizadas as viessem substituir, conquistando-as e cruzando-se com elas, e com outras trazidas d'além dos mares [...]". [VARNHAGEN, 1978, I:52.] Indolentes, instáveis e rebeldes, mostrar-se-1́am imprestáveis, ao trabalho produtivo sistemático. Eram arcaísmos históricos destinados a desaparecerem com o avanço da civilização. Fenômenos próprios à história da exploração da força de trabalho passavam a ser explicados como inelutáveis conseqüências de naturezas humanas diferenciadas.

No Quinhentos, o cativeiro era uma instituição com profundas e antigas raízes em Portugal. A caça ao escravo foi um dos incentivos da expansão marítima. Com ela, a escravidão ibérica assumiu um caráter etnicamente negro. "A expulsão dos mouros da Península Ibérica e os efeitos da peste negra tinham deixado o Sul de Portugal quase desabitado." [ARNOLD, 1983:26.] Africanos supriram esta carência. Com a produção açucareira nas ilhas atlânticas, outro pólo consumidor de cativos juntou-se ao mercado ibérico. Em 1482, iniciou-se a construção do empório escravista do castelo de S. Jorge da Mina. Em 1486, fundou-se em Portugal a Casa dos Escravos, para controlar o comércio escravista. [ALMEIDA, 1978:58, 63.] Quando da descoberta da América, havia muito que o comércio de cativos enriquecia as elites lusitanas.

Apenas chegado ao Novo Mundo, Colombo registrou que os pacíficos autóctones resultariam em bons "serviçais". Na segunda viagem, o Almirante permitiu a escravização dos nativos e propôs aos reis de Espanha que enviassem navios carregados de "cabeças de gado". Eles levariam, no torna-viagem, como pagamento, "escravos destes canibais". 
[COLOMBO, 1984:123.] Vespúcio, referindo-se à viagem transatlântica de 1499-1500, relatava com naturalidade: [...] e como já andava a gente cansada e fatigada, por ter já estado no mar cerca de um ano, [...] acordamos fazer a presa de escravos, e carregar os navios deles, [...] e fomos a certas ilhas, e tomamos à força 232 almas, e carregamô-las, e tomamos a direção de Castela, [...]." [VESPUCIO, 1984:61.]

Nos primeiros tempos, os comerciantes de pau-brasil serviram-se dos americanos para obterem a madeira e outros produtos. $\mathrm{O}$ elevado valor mercantil dos gêneros americanos permitia a remuneração do esforço e das mercadorias dos brasis com objetos europeus. Pequenas quantidades de nativos eram adquiridas e levadas para o Velho Mundo, como comprovam os registros da carga da nau Bretoa. A escravização de brasis antecede a própria colonização. Ao conceder as donatárias, D. João III permitiu a captura para a exportação - anual e gratuita - de algumas dezenas de cativos. Varnhagen lembra que se facilitava ao donatário cativar "gentios para seu serviço e de seus navios. Mandar deles a vender em Lisboa até trinta e nove (a uns mais que a outros) cada ano, livres de sisa que pagavam todos os que entravam". [VARNHAGEN, 1978:151.] Este fluxo de brasis para a Europa seria numericamente pouco significativo.

Quando da fundação das colônias, era antiga a tradição açucareira lusitana. No Trezentos, encontrávamos pequenos e médios engenhos na bacia mediterrânica. Da Sicília, a produção foi transplantada para o sul de Portugal, para a Madeira, para São Tomé e para o Brasil. Se possível, os recém-chegados erguiam canaviais e engenhos. A rendosa atividade assentava-se sobre o esforço servil. Os colonos introduziram no Brasil as técnicas e os métodos açucareiros aclimatados na Madeira. A produção de açúcar exigia duras e longas jornadas de trabalho. Os colonos pobres eram homens livres e vinham para o Novo Mundo para melhorarem de vida. Não se submetiam às duríssimas jornadas dos engenhos e canaviais. Portugal não possuía um excedente populacional capaz de sustentar as necessidades açucareiras. A solução "natural" foi transplantar o mesmo regime de trabalho utilizado nas plantações mediterrânicas e atlânticas. 


\section{Bom negócio}

A escravidão de brasis era a forma de trabalho que melhor garantia uma alta rentabilidade à economia colonial. Os colonos passaram a reduzi-los à escravidão. Gândavo comentava, em 1572: "Os moradores desta costa do Brasil todos têm terras de sesmarias dadas e repartidas pelos capitães da terra, e a primeira coisa que pretendem alcançar são escravos para lhes fazerem e grangearem suas roças, porque sem eles não se podem sustentar na terra [...]." [GANDAVO, 1965:125.] Nóbrega registrou igualmente: "[...] os homens que cá vêm não têm outra vida senão a dos escravos, que lhes pescam e buscam de comer, tanto domina aqui a preguiça [...].” [NÓBREGA, 1955:80.] Na terceira década do Quinhentos, quando os primeiros brasis começaram a ser feitorizados, havia quase cem anos que negro-africanos eram mercantilizados pelos europeus. As categorias "negro" e "escravo" tinham-se tornado sinônimos. Daí ser o americano feitorizado comumente chamado de "negro da terra". Desde o início do Quinhentos, alguns africanos integraram as tripulações dos navios lusitanos.

Africanos foram trazidos para o Brasil com os primeiros colonizadores ou introduzidos quando do início da economia açucareira. Em 1548, o alemão H. Staden participou da defesa da vila de Igaraçú, em Pernambuco, assediada - se acreditamos nele - por oito mil "selvícolas". Na defesa, participaram 90 "cristãos" e "trinta negros e escravos brasileiros". [STADEN, 1988:46.] Esta primeira população negra servil era insignificante, se comparada à americana. Os africanos eram empregados sobretudo nas tarefas domésticas e como capatazes. O inventário de Mem de Sá, terceiro governador-geral e talvez o então mais rico proprietário da Bahia, de 1572, registrou 259 escravos como parte do espólio. Apenas 18 homens e duas mulheres eram africanos - Guiné -. Pouco mais de 7\% da escravaria. [WETZER, 1972:236.]

As reservas tupinambás de cativos eram reduzidas. Em 1612, no Maranhão, um "principal" voltou de uma "guerra sangrenta que durara seis meses" trazendo onze escravos "de diversas nações". [ABBEVILLE, 1975:121.] Os brasis não conheciam a escravidão. O cativeiro é um fenômeno recente na história da Humanidade. Ele pressupôe um desenvolvimento mínimo das forças produtivas e das relações sociais de produção. $\mathrm{O}$ homem só escraviza seu semelhante quando pode apropriarse de parte dos frutos de seu trabalho. Quando o nível de desenvolvimen- 
to de uma sociedade permite que o cativo produza, em forma sistemática, o necessário para sustentar-se e um excedente para o senhor. Tal excedente justifica e financia os gastos e a preocupação com o controle e submetimento dos escravos. [MAESTRI, 1988:3-4.]

Os tupinambás capturavam inimigos para serem abatidos e devorados. O sacerdote d'Évreux afirmava que eles eram obrigados a trabalhar na horticultura, a caçar e a pescar para o senhor e que se alimentavam com os restos. [METREUX, 1950:236.] Jean de Léry relatava: "[...] se os reconhecem como bons caçadores e pescadores e consideram as mulheres boas para tratar das roças ou apanhar ostras, conservam-nos durante certo tempo [...]." [LERY, 1961:175.] Esta forma de cativeiro teria uma instância econômica transitória. As atividades produtivas masculinas - a caça e a pesca - , de resultados aleatórios, adaptavam-se mal à escravidão. A produtividade da horticultura era relativamente pouco desenvolvida. Nos momentos de abundância alimentar, os cativos produziriam algum excedente. Nos de dificuldade, mal conseguiriam sustentar-se.

Os tupinambás cediam uma "esposa" ao cativo. Ela responsabilizava-se de sua vigilância. O cativo tinha que se alimentar e contribuir para a alimentação da esposa-guardiã. Desconhecemos as razões que determinavam o momento da execução. $\mathrm{O}$ cativo podia ser mantido vivo, durante anos, antes de ser sacrificado. Os velhos e os prisioneiros feridos eram executados após a prisão. [METRAUX, 1950:226-48.] Os cativos podiam ser abatidos quando de ocasiões rituais. [FERNANDES, 1970:150.] É uma hipótese que alguns cativos - que não fossem sacrificados por motivos cerimoniais - se alimentassem com 0 que produziam e, nos momentos de bonança, com o excedente alimentar da aldeia. Tenderiam a ser abatidos nos momentos de carestia. As comunidades tupi-guaranis não haviam alcançado um estágio onde a produtividade do trabalho justificasse o não abatimento do prisioneiro $e$ a utilização como escravo produtivo. Devido a problemas de segurança, as aldeias manteriam vivos apenas pequenas quantidades de cativos.

Os brasis destinados ao sacrifício eram conhecidos como "índios de corda'. Métraux explica que nada os diferia fisicamente dos aldeães livres, a não ser "o colar conduzido ao pescoço, que consistia em grossa corda, dura como pau, da qual pendia, pela nuca, uma franja feita de cordeizinhos de extrema finura. Tão complicado era o nó que somente 0 
dono podia desmanchar. Soares de Sousa assegura que esses cordéis eram enrolados em torno do pescoço e também nos rins. De acordo com Thevet, o referido colar teria outra significação, que não era a de um símbolo de escravatura. Era um verdadeiro calendário". Ou seja, "frutos redondos", "ossos de peixes", etc., enfiados na "corda" marcariam o número de "luas" que o prisioneiro viveria antes do "banquete". [METRAUX, 1950:233.]

\section{Primeiras compras}

No início do Quinhentos, comerciantes compravam alguns cativos aos americanos. O mesmo fizeram os lusitanos ao fundarem as colônias. $\mathrm{O}$ mais pobre colono não viveria sem um cativo. O mercenário $\mathrm{H}$. Staden contava: "Eu tinha um selvagem, da tribo dos carijós [guarani], que me pertencia. Apanhava-me caça, e eu ia de quando em quando com ele à floresta." [STADEN, 1988:78.] Ao chegar à baia de Guanabara, em 1555, Villegaignon comprou aos tupinambás "trinta ou quarenta homens e mulheres margaiă" para trabalharem na construção das fortificações e em outras tarefas. [LERY, 1961:91] Dez ou 12 deles - "de nove a dez anos" - foram enviados para a França. [LERY, 1961:87.] Parte dos "índios de corda" era trocada por manufaturados. Para os lusitanos, tal comércio livrava os brasis da morte e trazia-os ao cristianismo.

Os tupinambás negavam-se a ceder todos os cativos. Em 1555, após o submetimento das aldeias americanas das cercanias de Salvador, os lusitanos exigiram que os brasis não devorassem, mas vendessem os prisioneiros. O ultimato determinava que "não matassem os contrários senão quando fossem à guerra, como soem fazer todas a nações, e se por acaso os cativassem, ou que os vendessem, ou que se servissem deles como escravos". [NAVARRO, 1988:197.] Muito logo, os reduzidos estoques de cativos aldeães mostraram-se insuficientes para as necessidades coloniais. Os engenhos consumiam grandes quantidades de braços.

Em 1551, o padre A. Pires referia-se a fazendas pernambucanas com "duzentos escravos". [NAVARRO, 1988:108.] Em 1627, o frei Vicente do Salvador afirmava que a Bahia tinha 50 engenhos e, para cada, corresponderiam "dez lavradores de cana". [SALVADOR, 1982:112.] Portanto, quinhentos e cinqüenta unidades açucareiras. Se tomarmos 60 escravos por engenho e 10 por lavrador, uma população servil de 8.000 
homens. [GORENDER, 1988:84; SCHWARTZ, 1988:256.] Se trabalharmos com uma taxa anual de reposição de $6 \%$, apenas a produção açucareira baiana consumiria, anualmente, 480 cativos. A população de uma grande aldeia. Não computados os mortos durante o apresamento, transporte, etc.

Em 1612, um ancião tupinambá relatava que os lusitanos, após se estabelecerem em Pernambuco, teriam afirmado que não "podiam viver sem escravos" e que, a seguir, "[os colonos] não se contentaram apenas com os escravos capturados na guerra". [ABBEVILLE, 1975:115.] O velho aldeão prosseguiu: "Mas não satisfeitos com os escravos capturados na guerra, quiseram também os filhos dos nossos e acabaram escravizando toda a nação [...]." [ABBEVILLE, 1975:115.] A contradição entre a necessidade de cativos da economia colonial e a capacidade das comunidades tupinambás de produzi-los foi o principal motivo de atrito entre lusitanos e brasis.

A legislação permitia que se feitorizassem apenas os brasis preados quando das "guerras justas" ou legalmente comprados aos nativos. Os colonos pressionavam os americanos para que cedessem um número crescente de cativos. Ao chegar ao Brasil, os jesuítas se pronunciaram em favor dos brasis "resgatados ilegalmente" e negaram os sacramentos aos colonos que não libertassem os "negros [da terra] salteados" [NÓBREGA, 1955:141.] Em 1550, Nóbrega escrevia de Porto Seguro: "Nesta terra todos os homens ou a maior parte têm a consciência sobrecarregada por causa dos escravos que possuem contra a razão, além de que muitos que eram resgatados aos pais [...]." [NÓBREGA, 1955:80.]

Em torno de 1566, D. Sebastião procurou coibir a escravização "ilegal" de brasis. Nas instruções que ditou, reconhecia que "pais" eram induzidos pela "força, manhas, enganos" a venderem seus "filhos". A legislação real restringia a venda de "filhos" a quando houvesse "extrema necessidade". Uma junta colonial facilitou tais transaçōes. Elas seriam válidas quando determinadas por "grande necessidade". Nóbrega se opôs à interpretação e lembrou que os brasis não vendiam os filhos antes da chegada dos colonos. [WETZEL, 1976:210.] A permissão da autovenda de maiores, quando de "grande necessidade", motivou também freqüentes abusos. [WETZEL, 1972:213.] 


\section{Bandeiras e descidas}

O padre Fernão Cardim lembrava que, durante a seca de 1583, em Pernambuco, "desceram do sertão apertados pela fome, socorrendo-se aos brancos, quatro ou cinco mil índios. Porém passado [o aperto] [...], os que puderam se tornaram ao sertão, exceto os que ficaram em casa dos brancos ou por sua, ou sem sua vontade." [CARDIM, 1978:199.] Nada impediria os colonos de afirmarem que os brasis se haviam vendido, por um prato de farinha, para não morrerem. Os colonos lançavam mão de métodos mais expeditos para suprirem suas necessidades, como incentivar as atividades bélicas inter-aldeãs. $\mathrm{O}$ estado de guerra permanente resultava numa maior produção de cativos.

Staden referiu-se a uma expedição tupiniquim contra os tupinambás que subjugou uma inteira aldeia. Os velhos foram devorados e "alguns jovens", comerciados "com os portugueses". [STADEN, 1988:94.] N6brega conta que era comum que barcos corressem as costas seqüestrando brasis desavisados que subiam a bordo para comerciar. As comunidades litorâneas eram assaltadas e carregadas por mar para serem vendidas nas capitanias. Em 1549, Nóbrega descreveu como podiam ser feitos os "saltos": "[...] fazem pazes com os negros para lhe trazerem a vender o que têm, e por engano enchem os navios deles e fogem com eles; e alguns dizem que o podem fazer por os negros terem já feito mal aos cristãos." [NÓBREGA, 1955:33.]

Em 1554, Staden, prisioneiro dos tamoios, registrou os motivos que inimizaram os naturais do Rio de Janeiro com os lusitanos. Contavam os tamoios que os colonos os teriam procurado para comerciarem. E eles "tinham ido, com muita confiança, aos navios e subido a bordo, como fazem ainda nos dias presentes com os navios franceses; quando os portugueses conseguiram um número suficiente deles a bordo, os assaltaram, amarraram [...]." [STADEN, 1988:93.] O Regimento do primeiro governador geral punia com a morte e a perda dos bens tais razias. Nos primeiros tempos, elas ensejaram a violenta resistência antilusitana.

Expedições penetravam os sertões à procura de brasis - entradas, bandeiras, descidas. Eles podiam ser trazidos para o litoral pela força ou engano. Não vingando em São Vicente a produção mercantil, os colonos especializaram-se na caça e exportação de nativos. Destacamentos de vicentinos, apoiados por brasis, varavam os sertōes e caiam como lobos 
esfaimados sobre as aldeias americanas. Em fins do Quinhentos, o padre Cardim contava que os tupi-guaranis tinham grande respeito aos jesuítas: "[...] e é tão grande este crédito que alguns portugueses de ruim consciência se fingem de padres [...] os trazem enganados, e em chegando ao mar, os repartem entre si, vendem e ferram [...]." [CARDIM, 1978:123.] As “descidas" se generalizaram quando as aldeias litorâneas escassearam ou retiraram-se para o interior.

Diversas causas ensejaram a transição da mão-de-obra brasílica à africana. A fundamental foi o rápido decréscimo populacional das comunidades do litoral acossadas pelos colonos. Gabriel Soares, em Notícia do Brasil, de 1587, refere-se à agonia das comunidades caetés que viviam em Pernambuco, quando do início da colonização. Elas teriam sido fortemente combatidas pelos "tupinambás", que vendiam aos "moradores de Pernambuco e aos da Bahia, infinidade de escravos, a troca de qualquer coisa, ao que iam ordinariamente caravelōes de resgate, e todos vinham carregados desta gente, a qual Duarte Coelho de Albuquerque por sua vez acabou de desbaratar". [SOUSA, s.d. I:116.]

Segundo Soares, preso entre os ataques dos lusitanos e dos tupinambás, "se consumiu este gentio [caeté], do qual não há agora senão o que se lançou muito pela terra dentro, ou se misturou com seus contrários". [SOUSA, s.d. I:116.] Observando e justificando o declínio demográfico dos nativos da costa, Gândavo afirmava ser impossível "numerar [...] a multidão do bárbaro gentio" que possuía o Brasil quando da descoberta e que, devido às "traições" dos brasis, os colonos "destruíram-nos pouco a pouco" resultando daí encontrar-se "a costa despovoada de gentio [...]". [GÂNDAVO, 1965:181.] Outras razões contribuíram e aceleraram a transição. A introdução de africanos permitia relações menos conflitivas com os nativos. Os brasis aculturados eram utilizados no controle das escravarias negras e na defesa da colônia. A heterogeneidade cultural africana era muitíssimo superior à dos nativos.

\section{Pele negra}

A pele negra identificava os cativos e "justificava", com um critério físico, a "natureza" servil dos africanos. Estes últimos desconheciam a terra onde eram escravizados. Dizia Gândavo que os "escravos de Guine" eram "mais seguros que os índios da terra porque nunca fogem nem têm 
para onde [fugir]". [GÂNDAVO, 1965:131.] O pleonasmo aparente "indio da terra" sugere que, para Gândavo, "índio" seria já sinônimo de escravo. Teríamos portanto o "índio da terra" e o "índio da Guine", como tínhamos o "negro da terra" e o "negro da Guiné".

O cativeiro indiscriminado dos brasis era combatido por Roma. Preocupado com a expansão muçulmana e a Reforma, o papado entregara às coroas ibéricas a responsabilidade da evangelização americana. Elas foram investidas de amplos poderes no Relativo à administração espiritual das conquistas. Quando compreendeu a extensão dos territórios e das populações americanas, Roma tentou - sem contraporse às coroas ibéricas - reconquistar uma parcela de poder espiritual e temporal cedido. Pronunciando-se a favor da humanidade dos americanos e contra a escravização indiscriminada, o papado construiu-se uma estratégia de longa duração. [HOORNAERT, 1979:160 et seq.]

A ação da Igreja punha travas à escravidão dos brasis. Os jesuítas compreenderam que os cativos dos colonos não sobreviviam e não eram cristianizados. A solução proposta foi a "aldeia de índio". A chegada de africanos diminuía a pressão dos colonos sobre os brasis. A substituição do nativo pelo africano era do interesse da Coroa e das classes mercantis. Os brasis escravizados não rendiam lucro direto à metrópole. Os colonos compravam-nos das comunidades aliadas ou aprisionavam-nos diretamente. No tráfico transatlântico, o africano era taxado ao embarcar na África e ao desembarcar no Brasil.

As primeiras leis coibindo seriamente a escravização indiscriminada de brasis foram feitas no reino de D. Sebastiâo, quando Portugal vivia sérias dificuldades econômico-financeiras. $\mathrm{O}$ tráfico negreiro fortalecia as finanças reais. $\mathrm{O}$ comércio tumbeiro propiciava o chamado "comércio triangular". Os navios saíam da Europa abarrotados de mercadorias. Elas eram trocadas, nas costas africanas, por homens, mulheres e crianças. Os negreiros permutavam os cativos pelos produtos coloniais, que eram vendidos, a alto preço, na Europa. A venda da produção colonial permitia que os colonos comprassem africanos e mercadorias européias.

Um outro fenômeno, próprio ao continente africano, desempenhou um papel essencial nesta transição. Antes mesmo da chegada dos europeus, a África conhecia um amplo movimento de circulação - local, regional e internacional - de cativos e de mulheres. [MEILLASSOUX, 
1975:509-28.] Este fluxo demográfico se adaptou "naturalmente" ao tráfico transatlântico de cativos. Reinos negros escravizadores organizaram-se na costa para fornecer escravos aos europeus. A África mostrou-se um reservatório inesgotável de homens que eram oferecidos nos portos escravistas. A verdadeira especialização da produção de cativos - captura, armazenamento, embarque, transporte, venda permitiu um fornecimento ininterrupto e abundante de braços escravizados. [MAESTRI, 1988:38 et seq.]

O tráfico negreiro pacificava relativamente o litoral. Despreocupados com o apresamento aleatório e perigoso de brasis, os colonos especializavam-se na produção de bens coloniais. As necessidades de um abastecimento crescente, seguro e sistemático de braços escravos e a dizimação dos brasis teriam portanto criado as bases para a perda de importancia relativa do "negro da terra" diante do "negro" da África. Como vimos, a partir dos anos 70 do Quinhentos, as regiōes coloniais mais ricas começaram a ser abastecidas pelo tráfico negreiro. Nas primeiras décadas do século seguinte, o processo de substituição já se realizara nas capitanias mais ricas.

\section{Bibliografia}

ABBEVILLE, Claude d'. História da Missão dos Padres Capuchinhos na Itha de Maranhão, e terras circunvizinhas. São Paulo, Martins, 1945. [1.ed., 1614.]

ALMEIDA, Pedro Ramos de. História do Colonialismo Português em África. Cron. séc. XV-XVIII. Lisboa, Estampa, 1978.

ANCHIETA, José. Cartas. Correspondência ativa e passiva. Pesquisa, introđução e notas de H.A. Viotti. São Paulo, Edições Loyola, 1984. [Obras Completas, 6.]

ARNOLD, David. Épocas dos Descobrimentos. 1400-1600. Lisboa, Gradiva, 1983.

[BRANDÃO, A.F.] Diálogos das Grandezas do Brasil. São Paulo, Melhoramentos, 1977.

BROCHADO, José Proenza. "Um modelo ecológico de difusão da cerâmica e da agricultura no leste da América Latina". Urbana, Illinois, 1984. [Tese de doutoramento: ex. xerocopiado.]

CARDIM, Pe. Fernăo. [ca. 1540-1625]. Tratado da Terra e Gente do Brasil. 3.ed. São Paulo, C.E.N.; Brasília, INL, 1978.

COLOMBO, Cristóvão. Diário da Descoberta da América. As quatro viagens e o testamento. Porto Alegre, L\&PM, 1984.

DIAS, Carlos Malheiro. (Org.). História da Colonização Portuguesa no Brasil. Edição monumental comemorativa do I Centenário da Independência do Brasil. [HCPB]. Porto, Litografia Nacional, MCMXI. (3v.)

DIAS, Manuel Nunes. O Descobrimento do Brasil. São Paulo, Pioneira, 1967.

EVREUX, Ivo d'. Viagem ao Norte do Brasil. Rio de Janeiro, Leite Ribeiro, 1929. 
FBRNANDES, Florestan. A Organizaçåo Social dos Tupinambás. Săo Paulo, Progresso, [1948].

-. A Função Social da Guerra na Sociedade Tupinambá. 2.ed. Săo Paulo, Pioneira, 1970.

GARCIA, José M. (Org.). Vlagens dos Descobrimentos. Lisboa, Presença, 1983.

GÂNDAVO, Pêro de Magalhăes de. Tratado da Províncla do Brasil. Rio de Janeiro, INL/Ministério da Educaçăo e Cultura, 1965.

GORENDER, Jacob. O Escravismo Colonial. S.ed. Såo Paulo, Ática, 1988.

HOORNAERT, E. et alil. História da Igreja no Brasil. Ensaio de interpretaçăo a partir do povo. Primeira época., 2.ed. Petrópolis, Vozes, 1979.

LERY, Jean de. [1534-1611].Vlagem à Terra do Brasil. Trad. S. Milliet. Săo Paulo, Biblioteca do Exército, 1961. [1.ed., 1587.]

LEITE, S.I. Serafim. História da Companhia de Jesus no Brasil. I. Lisboa, Portugália; Civilizaçăo Brasileira, 1938.

MAESTRI, Mário. Servidảo Negra. Porto Alegre, Mercado Aberto, 1988.

- História da África Negra Pré-Colonial. Porto Alegre, Mercado Aberto, 1988.

-. O Escravismo Antigo. 7.ed. São Paulo, Ática, 1989.

MARCHANT, Alexander. Do Escambo à Escravidäo. As relações de portugueses e ínđios na colonizaçăo do Brasil. 1500-1580. Săo Paulo, CEN; Brasilia, INL, 1980.

MEILlASSOUX, Claude. (Org.). L'Esclavage en Afrique Précoloniale. Paris, Maspero, 1975.

-. Mulheres, Celeiros \& Capitais. Porto Alegre, Afrontamento, 1977.

METRAUX, Alfred. A Religiẩo dos Tupinambás. E suas relaçōes com a das demais tribus tupi-guaranis. Trad. Estevăo Pinto. Săo Paulo, CEN, 1950.

NAVARRO, Azpilcueta et alli. Cartas Avulsas. 1549-1560. Belo Horizonte, Itatiaia; Săo Paulo, EDUSP, 1988.

NÓBREGA, Manuel đa. [1517-1570]. Cartas do Brasil. 1549-1560. Belo Horizonte, Itatiaia; Săo Paulo, EDUSP, 1988.

-. Cartas do Brasil e mais Escritos. It. e notas Serafim Leite. Coimbra, Universidade de Coimbra, 1955.

SALVADOR, Frei Vicente do. [1554-1636/9]. Hist6ria do Brasil. 7.ed. Belo Horizonte, Itatiaia; Săo Paulo, EDUSP, 1982.

SCHWARTZ, S.B. Segredos Internos. Engenhos e escravos na sociedade colonial. São Paulo, Companhia das Letras, 1988.

SIMONSEN, Roberto C. [a-1948]. Hist6ria Econômica do Brasil. ](1500-1820). 7.ed. Sảo Paulo, CEN; Brasilia, INL, 1977.

SOUSA, Bernardino José de. O Pau-Brasil na Historia Nacional. 2.ed. Săo Paulo, CEN; Brasilia, INL, 1978.

SODRÉ, Nélson Werneck. Historia da Literatura Brasileira. Seus fundamentos económicos. S.ed. Rio đe Janeiro, Civilizaçăo Brasileira, 1968.

STADEN, Hans. Duas Vlagens ao Brasll. Trad. G.C. Franco. Belo Horizonte, Itatiaia; São Paulo, EDUSP, 1974. [1.ed., 1557.]

THEVET, André. Singularidade da França Antártica. A que outros chamam de América. São Paulo, CEN, 1944. [1.ed., 1558.]

-. La Cosmographie Universelle d'André Thevet. Comosgraphie du Roy. In: Les Françals en Amérique. Pendant la deuxième moitié du XVI siècle. Le Brésil et les Brésiliens. Paris, PUF, 1953. 
VARNHAGEN, Francisco Adolfo. [1516-1878]. História Geral do Brasil. 10.ed. São Paulo, Melhoramentos, 1979. Tomo I.

VESPÚCIO, Américo. Novo Mundo. Cartas de viagens e descobertas. Porto Alegre, L\&PM, 1984.

WETZEL, Herbert Ewaldo. Mem de Sá. Terceiro governador geral. Conselho Federal de Cultura, Rio de Janeiro, 1972. 